\title{
EL ESPACIO COMUNICATIVO EN EUROPA
}

\author{
M.a ANTONia Martín DíEz \\ Profesor titular de Periodismo. Universidad Europea de Madrid
}

\section{Resumen}

La integración europea ha ido dando pasos adelante desde el fin de la II Guerra Mundial hasta nuestros días. La comunicación ha sido uno de los instrumentos utilizados para ello. Así por ejemplo, el primer objetivo de la política de comunicación del Consejo de Europa y de la Unión Europea ha sido forjar una identidad común para cuya consecución se han promulgado disposiciones de diverso tipo. A concienciar dicha identidad ha ayudado mucho la irrupción masiva de la tecnología audiovisual y la política audiovisual cuyo carácter global ha mostrado una notable efectividad en diversos campos.

\section{Palabras clave}

Políticas de comunicación, política audiovisual europea, integración europea

\section{Abstract}

European integration has moved forward since the 2nd World War till present. Communication has been one of the tools that has been most often used with a view to reach this objective. For instance, the main objective of the communication policy of the European Council and the European Union has been that of building a common identity and enacting different shorts of dispositions with a view to reach this goal. The massive spread of audiovisual technologies and the new audiovisual policies, whose global scope has proved highly effective in different fields, have contributed enormously to raise public awareness of the common identity

\section{Key Words}

Media policy, European audiovisual policies, European integration. 


\section{INTRODUCCIÓN}

La idea de Europa ha tenido en la historia diferentes concepciones. Los conocimientos que se tuvieron en el Viejo Continente de su antiguo pasado fomentaron una conciencia de universalidad. Europa abarcaba todo el mundo conocido. Más tarde se pasó a una concepción etnocéntrica que estuvo basada en las colonizaciones. En nuestro tiempo se aspira a que Europa sea un espacio de cooperación, bienestar social y progreso. De esta forma lo define el Proyecto de Tratado por el que se instituye una Constitución para Europa. Se dice en el Preámbulo que la Europa ahora reunida, avanzará por la senda de la civilización, el progreso y la prosperidad en bien de todos sus habitantes, sin olvidar a los más débiles y desfavorecidos; que esa Europa quiere seguir siendo un continente abierto a la cultura, al deber y al progreso social; que desea ahondar en el carácter democrático y transparente de su vida pública y obrar en pro de la paz, la justicia y la solidaridad en el mundo.

Europa se consideró universal, porque lo llevaba consigo el pensamiento filosófico griego, la acción imperial romana y la formulación más acabada de la lglesia católica. La conjugación de los anteriores elementos conducirá a la creación del Sacro Imperio Romano Germánico.

Europa ha sido también etnocéntrica, por varias razones:

1. porque el hombre europeo vivió su existencia como eje de la Humanidad. Los hallazgos de Copérnico, Galileo, Darwin, Freud y Einstein constataron limitaciones pero no destruyeron la creencia de "superioridad" del europeo.

2. porque la cultura europea se impuso como modelo en la expansión colonial.

3. porque los conciertos políticos, desde el Congreso de Viena, desarrollaron junto a la concepción del Estado-nación, la idea de un orden mundial basado en Europa.

4. porque la génesis de la civilización occidental y el sentido de una comunidad atlántica han seguido vinculados a los valores europeos de libertad, justicia y solidaridad.

La idea de unidad de Europa, bastante real en la sociedad medieval, pero sólo como objetivo que había que alcanzar en siglos posteriores, se convirtió, desde 1945, en una necesidad y, desde la década de los setenta, en una urgencia.

Hemos dicho bastante real, porque es en la sociedad medieval donde florecieron el libre tránsito, la unidad religiosa y, en el campo académico, la unidad lingüística. También esa unidad se aprecia en el arte como puede verse a título de ejemplo al examinar la geografía del gótico.

Objetivo ideal, hasta 1945, porque así fue el pensamiento de Coudenhove-Kalergi, cargado de utopía, en su convencimiento de que la integración europea se haría por una decisión de carácter político. En ningún momento este calificativo desea desprestigiar la gran aportación del Mo- 
vimiento Pan-Europeo y de su revista Pan-Europa. Esta publicación será la primera aportación de un medio de comunicación de masas en favor de la construcción europea.

Objetivo ideal fue también el propósito de Aristides Briand en la Sociedad de las Naciones. Mil novecientos veintinueve quedará en el recuerdo de la opinión pública europea, más como el año de la recesión económica mundial que como el año de Europa. Sin embargo, aquel esfuerzo no fue baldío. Con la creación de la Comisión Internacional de Cooperación Intelectual se intentó potenciar la cooperación con mayor vigor en Europa aunque también incluso, a escala universal.

En concreto, la formación del Instituto Internacional de Cooperación Intelectual (Francia, 1926), va a potenciar entre 1926 y 1940 el desarrollo de centros y comités especializados en temas comunicativos como la prensa de los estudiantes, el cine, la radio y la prensa en general. Debemos destacar especialmente la Comisión Internacional para la Enseñanza Cinematográfica, el Congreso Internacional de Cine (1926), la Revista Internacional de Cine Educativo (1934), con cinco ediciones en alemán, francés, español, inglés e italiano y la edición posterior de Intercine, aunque sólo tuviera un año de vida (Valderrama, 1995).

La unidad de Europa fue una necesidad, desde 1945, como apareció en la célebre conferencia de Churchill en la Universidad de Zurich. Sus motivaciones eran el mantenimiento de la paz, el fortalecimiento del estado de derecho y la potenciación de los valores europeos de libertad y justicia. Tras el Congreso de la Haya de 1948 nació el Consejo de Europa en donde la cooperación interestatal, salvo en el campo defensivo, fue el objetivo prioritario.

El Consejo de Europa optó por una cooperación basada en el estado de derecho en cuyo concepto entran decididamente los valores básicos de la Europa Occidental. En esta línea, la política de comunicación fue básicamente dirigida a los líderes de opinión. Dar a conocer el estatuto fundacional y sus instituciones fueron los primeros objetivos avalados por la información que cada Estado miembro daba del Consejo de Europa. En segundo lugar, se produjo la creación de símbolos comunes: la bandera, el himno y el día de Europa (modificado luego por la Unión Europea), perfilando ya el deseo de una identidad común. Y así persistieron las acciones anteriores en su difusión junto a la gestión propia de un departamento de comunicación (comunicaciones, visitas a sede, ruedas de prensa, creación de antenas, etc).

A la política de información y comunicación sirvió notablemente el establecimiento de un Tribunal para la protección y salvaguarda de los derechos humanos. El ámbito jurídico presenta al Convenio para la Protección de los Derechos Humanos y de las Libertades Fundamentales impulsado por el Consejo de Europa, como un modelo universal que hay que seguir. La difusión de los casos presentados y sus sentencias convierten a los Estados en pacientes sumisos del Tribunal de los Derechos Humanos operativo en el marco del Consejo de Europa. Sumisos, porque los propios medios públicos participan en la campaña de difusión y toman parte en la creación de una opinión pública que tiene como referente crítico frente a su Estado, la posibilidad de amparo. Tras los pasos dados por el Consejo de Europa, otras Organizaciones Europeas seguirán impulsando la construcción de Europa. 
Consideración muy especial merece, entre todas ellas, la Unión Europea, por ser la Organización más avanzada en el proceso de integración.

La Unión Europea partió de la concepción de una Europa necesaria. Necesidad basada en la lógica de los valores. Valores son asegurar la paz y proteger el Estado de derecho y el bienestar social de la población. También la Unión Europea deseó imperiosamente asegurar la posición de liderazgo en el contexto mundial y mantener una cultura propia.

Esta necesidad precisó ir creando una identidad europea, identidad que presenta todavía su complicación al ser el marco geográfico europeo un lugar donde conviven diferentes identidades nacionales tanto estatales como no estatales. Una combinación que puede quedar muy armónica si se entiende integrada de forma piramidal. Europa será, la Europa comunitaria, la Europa de las naciones, la Europa de las regiones, la Europa de los municipios y en última instancia la Europa de los ciudadanos, ámbitos conjugados por el principio de subsidiariedad (Martín, 2000: 57-64).

\section{COMUNICACIÓN E INTEGRACIÓN}

En relación con los procesos de integración podemos destacar dentro de las diversas teorías existentes, el modelo de la escuela de la Teoría de la Comunicación, dirigida por K. Deutsch, por su diseño de "comunicación internacional en cascada", por su reconocimiento del poder político y por su capacidad de cuantificar el poder sobre la base de las transacciones (Sahún, 1998: 197. 219). La vigencia de su modelo y su planteamiento de la participación del individuo en el proceso resulta todavía innovadora.

Para Deutsch, son el flujo y la transacción lo que hace que los hombres sean interdependientes. Y es la interdependencia lo que lleva a la integración. Respecto al proceso comunicativo afirma: "La comunicación es el cimiento de la organización. Sólo la comunicación hace a los miembros pensar, comportarse y observar juntos dentro de un grupo" (Deutsch, 1964: 77).

Personalmente, creemos que el modelo debía adaptarse en la actualidad para constituir realmente la integración europea, suponiendo como desarrollo, la potenciación de las industrias culturales, la identificación de los grupos de comunicación con el modelo europeo y la concienciación de la identidad europea como contrapartida a los efectos nocivos de la globalización (Martín, 2000: 57-64). Desde sus orígenes como CECA hasta su constitución actual como Unión se ha recorrido un largo camino, pero se está todavía en proceso.

Forjar una identidad común es el principal objetivo de la política de comunicación de la Unión Europea. Si bien es cierto que esta política ha sido tipificada como tecnocrática, dirigista, fría e inadecuada por el Parlamento Europeo en crítica a la Comisión, también es cierto que es la que ha involucrado a más medios en esta labor. El problema de fondo no es ni nuevo ni actual. Ya viene de muchos años atrás. Ya Ortega y Gasset, en 1926, se sublevaba contra la cultura ex- 
portada por los Estados Unidos. Más que cultura era una pseudocultura y estaba así sometida únicamente a las leyes de producción-distribución masiva y a la tecnología. A Ortega le parecía que la elevada cultura de las Luces creada en el Viejo Continente recibía así un ataque frontal que debía ser frenado. El pensador español negaba, en el período de Entreguerras, que los Estados Unidos tuvieran capacidad de "sucederle a Europa en el mando del mundo". Se refería, sobre todo, a un mando intelectual. Un mando que, cuando lo tenía Europa, imponía en el mundo un valioso principio de universalidad (Mattelart, 1993: 101).

En 1973 se inició en EEUU la liberalización financiera. Tras ella fue la liberalización de las comunicaciones la que nos introdujo en la sociedad global. El concepto de sociedad global se equipara al concepto de sociedad postindustrial de Bell y Touraine, al de sociedad tecnotrónica de Brezezinsky, al de sociedad de consumo de Jones y Baudrillard, al de sociedad informatizada de Nora Minc, al de sociedad interconectada de James Martin, al de Estado telemático de Gubern, al de tercer ola de Alvin Toffler, al de la aldea global de Mac Luhan, al de sociedad digital de Merecier - Plassard - Soardigly - Bustamente - Negroponte y Terceiro y al de cibersociedad de Joyanes Aguilar (Joyanes, 1997: 84).

Europa tuvo que reaccionar ante la competencia y la presión exterior. Como respuesta inició la liberalización de las telecomunicaciones en las áreas de desarrollo de estándares, investigación e incentivación de la política de desarrollo regional. En 1987, la Comisión publicó el Libro Verde sobre el desarrollo de un mercado común para los equipos y servicios de telecomunicaciones, que concluiría con el establecimiento para el 1 de enero de 1998 de la liberalización del sector. Sin embargo, todavía se mantienen diferencias entre los Estados miembros en: los porcentajes de privatización de los operadores tradicionales, en las tarifas de precios de productos básicos, en la concepción de servicio universal e interés público y en los procedimientos de privatización (Castejón, 1998: 29-48). Pese al establecimiento de políticas convergentes donde se incluyen los ámbitos de comunicación, información y telecomunicación aún se mantiene la dicotomía en las acciones comunicativas y de infraestructuras. Este hecho debilita la acción comunicativa de la Unión especialmente cuando el "Protocolo sobre el sistema de radiodifusión pública" del Tratado de Ámsterdam considera la comunicación como propia de cada Estado. Sin embargo, aquí aparece también un aspecto universal en cuanto que la sociedad global es universal (Mattelart, 1997:117)'. El aspecto etnocéntrico sigue siendo una realidad pero se constata no como un monocentrismo europeo sino como un policentrismo de las diversas naciones de Europa.

Ante la nueva realidad, sin querer parodiar a Drucker, el Consejo de Europa afronta la problemática ante el desarrollo tecnológico de las telecomunicaciones, el poder de los medios de comunicación y las expectativas o demandas de las audiencias.

De acuerdo con A. Mattelart, aunque la liberalización de las actividades bancarias comenzó en los años setenta en los EEUU no se extendió realmente hasta 1984, a partir del desmantelamiento de la ATT (American Telegraph \& Telephone), consagrándose desde entonces el término globalización como coincidente con la liberalización y privatización de las redes de comunicación. 


\section{LA IRRUPCIÓN MASIVA DE LA TECNOLOGÍA AUDIOVISUAL}

Desde 1980 ya no es suficiente plantearse el problema de qué es Europa o cómo lograr la integración europea. Un mercado publicitario boyante empuja a los grupos de comunicación en sus reivindicaciones frente al poder político. A este hecho se suma la pérdida de soberanía que supone la tecnología vía satélite y las cuestiones internacionales surgidas por las políticas nacionales en controversia. Europa se encamina hacia un nuevo modelo audiovisual, con la pérdida de los monopolios públicos. Es éste un cambio que se iniciará caóticamente en Italia, aprovechando un vacío legal y que cuestionará, en 1983, no sólo el derecho de emisión del servicio público sino su propia subsistencia con el duopolio RAI, Berlusconi. El paso siguiente dado por el gobierno de Mitterand en Francia también supone una merma del tejido audiovisual público. Esta tendencia hace que en Europa, la nueva situación de convivencia de medios públicos y privados, dure hasta el año 1994 con la renuncia obligada del Gobierno austriaco, previa sentencia del Tribunal Europeo de los Derechos Humanos. La nueva regulación del audiovisual, mantiene como necesaria la existencia de los sistemas públicos. Sus argumentos también han evolucionado conforme a los cambios comunicativos y tecnológicos. Ya no se basan en la existencia de monopolio del espectro electromagnético con sistema similar al radiotelégrafo y a la radiodifusión, ni en la cobertura total de zonas oscuras, o en la programación para todos los públicos. Tampoco en las clásicas funciones mediáticas de informar, formar y entretener. Nacida la neotelevisión, al servicio público le resulta costoso mantenerse fuera de los deseos de la audiencia cuando ha caído en las redes de la "televisión basura" concepto que en inglés responde a la voz de "trash tv" y que también se ha traducido por "televisión asquerosa, gore, repleta de sexo y violencia...de usar y tirar" (Pérez, Jiménez, 2002 : 197). Pero sí puede fundamentarse en la necesidad de mantener la pluralidad de opiniones y espacios de alto coste de cobertura, carentes de publicidad, por su larga emisión pero con alta demanda social, aunque se trate de eventos esporádicos como son las visitas papales. La actuación comunicativa del Consejo de Europa se encamina al diseño de una política audiovisual común.

El Convenio de la Televisión Transfronteriza con el que el Consejo de Europa celebró su cuadragésimo aniversario sirvió como modelo en la definición de conceptos como el de obra europea posteriormente aceptados por la Directiva de la Televisión sin Fronteras de la Comunidad Europea.

El Convenio sigue pendiente de ratificación por la mayoría de los Estados miembros, hecho que menoscaba su efectividad. Sin embargo marca las pautas para una integración de los países de Europa Central-Oriental, las limitaciones a cierto tipo de publicidad (tabaco, alcohol) y la protección de los menores respecto al medio.

Con anterioridad al Convenio, el Consejo de Europa había adoptado en relación con la comunicación, dos Declaraciones. La Declaración sobre Medios de Comunicación y Derechos del Hombre (1970) y la Declaración sobre la Libertad de Expresión e Información. Había organizado diversas Conferencias Ministeriales, como la Conferencia de Estrasburgo sobre "democracia parlamentaria" una parte de la cual fue destinada al tema de la opinión pública. Es el informe sobre el papel de los medios de comunicación. Se celebraron, además, las Conferencias Ministeriales Eu- 
ropeas sobre políticas de comunicaciones de masas (Viena, 9 y 10 de diciembre de 1986 y Estocolmo, 23 y 24 de noviembre de 1988).

De esa forma se aprobaron diversas resoluciones y recomendaciones entre las que destacaron la de intercambio de programas y la utilización educacional de la radio y la televisión en Europa. Fue sin embargo, la Resolución de Creación de un gran Espacio Cinematográfico y Televisivo la que llevaría a la creación de Eurimages como instrumento ${ }^{2}$. Eurimages otorga ayudas a la coproducción, distribución y salas de exhibición de las obras cinematográficas europeas. Financiado por las contribuciones de los Estados miembros ha conseguido hasta la actualidad, la coproducción de numerosos documentales.

A instancia francesa nació Eureka Audiovisual, como organización intergubernamental, con 34 Estados miembros y de la Comisión Europea como miembro socio, con el objeto de establecer un espacio europeo de cooperación e intercambio en el sector audiovisual. Desde 1996, la Organización ha venido dedicándose a acciones favorables a los países de Europa Central Oriental, y meridional. El 23 de noviembre de 1999, se aprobó la Declaración Elounda, en la que se establecieron como objetivos de futuro: el efecto de la revolución digital en la producción y distribución de obras audiovisuales y cinematográficas, el mantenimiento de las identidades culturales, la diversidad de imágenes y la ampliación de la inversión de fondos públicos y privados en el audiovisual. La importancia de las industrias culturales, especialmente en el sector de la ficción televisiva, precisa de la capacidad productora y del tejido industrial de los sistemas públicos. Para la Unión Europea su acción es contingente: para desarrollar su competencia en los aspectos culturales (concretamente, la mejora del conocimiento y de la difusión de la cultura y la conservación y la salvaguardia del patrimonio cultural, los intercambios culturales y la creación artística, según el art. 151 del tratado de la $C E$ ), para el desarrollo de los aspectos culturales y educativos de la sociedad de la información y para la propia política informativa sobre sus actividades. Tal y como apuntaba Enrique Bustamante, la política audiovisual tiene que ser conjunta e integrada. No se puede pensar en las políticas sectoriales como elementos independientes. Aunque "la televisión especialmente, en sus diversas modalidades de soporte y financiación, es un capital de toda estrategia de futuro, la política audiovisual pasa por las telecomunicaciones (Bustamante, 1995: 47). La Organización cuenta desde el año 2000 con un presupuesto comunitario reforzado para las acciones en los países balcánicos y euromediterráneos, apostando por el refuerzo de la acción formativa ${ }^{3}$.

La culminación del objetivo final, como siempre que se establecen políticas de coordinación, era necesaria. El audiovisual se entendía como propio, diferenciado del ámbito de la comunicación ante las nuevas realidades. Como ha escrito Mariano Cebrián, "un sistema audiovisual es un intermediario entre la sociedad que lo pone en marcha y el público que recibe su actividad o que lo soporta" (Cebrián, 1998: 21).

\footnotetext{
El nombre de Resolución sustituyó al de Recomendación desde 1978.

http://www.aveureka.org
} 
Las nuevas realidades eran de carácter tecnológico (la implantación de la televisión vía satélite), social (la disconformidad de la audiencia con la televisión paternalista pública), político (los intentos de crear una Federación socialista en Europa), cultural (mayor pluralidad en la oferta), económico (despertar de nuevas áreas de negocio y configuración de los grupos multimedia) y sobre todo, internacional (la respuesta europea a la "uniformización"cultural).

La televisión vía satélite empezó a ser masiva en la década de 1980. En 1956 se inició desde planteamientos paraestatales la carrera por el control de los satélites. Planteada en el contexto de guerra fría pronto vio surgir sus correspondientes lineamientos: INTELSAT e Interspucnik. La respuesta europea dada a conocer en 1973 en Naciones Unidas, de desarrollar sus propios satélites se concretó unida a los monopolios de telecomunicación en Eutelsat.

No ocurrió lo mismo con el Fondo Euroimages. Las críticas referidas a su existencia fueron dirigidas a su escasez presupuestaria pero su vigencia inicial fue defendida en la medida en que era la única opción de financiación externa para los países de Europa Oriental aunque se forzase la necesidad de coproducción con terceros países.

El Consejo de Europa no sólo fue pionero en la concepción de promocionar, incentivar o crear (dependiendo de los autores), una industria audiovisual europea, sino que también lo fue en definir su posición respecto a la concentración de medios. Esta labor fue modélica en la medida en que los Estados miembros estuvieron optando por medidas laxas frente a la concentración, tratando de reforzar los grupos nacionales de comunicación, para que a su vez los grupos apoyaran la política de comunicación de éstos. Esta situación, en opinión de A. Sánchez-Bravo, "dificulta la creación de una opinión pública europea plural, proyectiva y entusiasta de la idea de integración" (Sánchez Bravo, 1993: 93). "Políticas desreguladoras de los Estados y proyecto transnacional -afirman Enrique Bustamante y Ramón Zallo-, son fenómenos directamente imbricados, que no pueden entenderse sin esa relación mutua", dentro del análisis de las tendencias de las industrias culturales: la concentración y la internacionalización (Bustamente, Zallo, 1988: 14).

La concentración se abordaba como una pérdida del poder político pero con la ambivalencia que conllevaba la descripción paralela de efectos positivos y negativos. La clasificación de los tipos de fusión e integración era todavía un modelo a seguir aunque se creyera cada vez más que en el futuro sólo se hablaría de integración multimediática, dando por hecho las características de internacionalización e incluso de su vinculación multisectorial.

El Consejo de Europa recogió tibiamente los postulados de la escuela crítica frente al imperialismo cultural estadounidense (Wolf, 1994: 90-98). O si se prefiere, asumió la crítica explícita que el gobierno francés había defendido en 1982 en el marco de la UNESCO (Sánchez Tabernero, Zunzunegui, 1944: 53). De modo encubierto el espacio europeo se delimitó por primera vez en un documento de la Unión, en competitividad con otro mercado: el americano.

El Consejo de Europa ejerció con estos planteamientos, la función complementaria teórica de otra Organización: la Unión Europea. 
En el campo de la comunicación, la Unión Europea es la única Organización, en el ámbito mundial, que con propiedad realiza una política que en verdad pueda llamarse de comunicación. Sánchez Martínez cree, sin embargo, que la Comisión no entiende realmente la comunicación como información más retroalimentación, sino como información más "las relaciones significativas encaminadas a que la audiencia entienda de un cierto modo ese conocimiento" (Sánchez Martínez, 1999: 201). Diríamos que las otras Organizaciones plantean políticas informativas, propagandísticas o desinformativas pero no comunicativas en la medida en que no participa el receptor, aunque no lo sea ni en su iniciativa, ni en su elaboración pero sí en sus efectos. La razón se encuentra en la puesta en marcha de una publicación nacida justo en 1973: el Eurobarómetro. La entonces Comunidad Económica Europea inició un seguimiento sostenido de la opinión pública en su ámbito. El Eurobarómetro, que pronto pasó de la periodicidad anual a la semestral, ha ido evaluando el conocimiento que los ciudadanos comunitarios tienen de sus instituciones y, lo más importante, su sentimiento o grado de adhesión a Europa.

Los sondeos del Eurobarómetro se intensificaron cuando se celebraron las primeras elecciones al Parlamento Europeo. Sin embargo estas acciones, junto con las del Consejo de Europa, más las propias de un gabinete de comunicación, no surten efecto en la opinión pública. Es curioso cómo, incluso antes de las nuevas adhesiones de Estados a la Unión Europea, la acción de la Comisión puede crear un clima de opinión y levantar expectativas. Tal es el caso de la campaña creada en Turquía y su interpretación propagandística en relación con su posible adhesión.

Hecho similar ocurre con el llamado efecto Presidencia. En este último caso, durante esos seis meses, la acción comunicativa de la Comisión se suma a la propaganda interna del país, llevando a cabo una campaña de gran alcance especialmente cuidada con la celebración del Consejo Europeo. Sin embargo vemos excepciones al mismo, habituales como es el caso de Gran Bretaña o coyunturales como el de Portugal (Martín, 1998: 72).

Sí que es apreciable el efecto en los medios de comunicación de los Presidentes de la Comisión. Basta recordar la figura emblemática de Jacques Delors. Con Delors la política de propaganda dentro de la Comunidad Europea se hizo de muchas formas, incluidos los une con los eventos deportivos, buscando en su difusión lo público y lo festivo. Aunque el cambio más fuerte se apreció en la comunicación frente a terceros países. El Eurobarómetro suele preguntarse cómo nos ven los americanos, los polacos, los rusos o los húngaros. Delors, sin querer, aparecía en los medios de comunicación como el presidente de Europa, figura necesaria generadora de credibilidad y emotividad en la ciudadanía.

Pero todos sabemos que la presidencia y sus efectos son efímeros y a Delors le siguió Jacques Santer culminando en escándalo la última fase de su mandato.

La personalización y colaboración con el público propia de la globalización entró también en esta acción de la Comisión. Actualmente, hablar del Eurobarómetro supone el conocimiento de tres publicaciones. El citado y clásico Eurobarómetro, creado por Jacques Rabier, con el seguimiento de los modelos de integración, identidad y conocimiento de las instituciones comunitarias, 
dirigido por el Instituto INRA de Bruselas. El margen de error permitido en sus trabajos no puede superar el 3 '5 \%. En segundo lugar, para los temas de interés específicos y ocasionales se preparan por EOS Gallup Europe en Bruselas, el Eurobarómetro Flash, con el mismo margen de error permitido que el anterior. Últimamente se han introducido otras dos encuestas: los sondeos a líderes de opinión, que se publican bajo el nombre de Eurobarómetro mensual de Control y la Encuesta de seguimiento continuo, realizada por la Dirección General X, con técnica de panel, consistente en un seguimiento de seis días por semana durante las cuatro semanas de un mes. Permite un margen de error del 3,5\% y es coordinada por Euroquest MRB en Londres.

Debido al escaso presupuesto para la comunicación, si lo comparamos con el de países como EEUU, o como Gran Bretaña, la labor expuesta hasta aquí no justificaría la acción comunicativa de la Unión Europea, o si se prefiere con más precisión, la de la Dirección General X. La actitud conservadora de los Estados por mantener su espacio de soberanía en el ámbito de la comunicación resta efectividad a los mensajes de esta Dirección. "La Comunidad Europea -afirma S. Herrero-, es una negociación entre doce Estados miembros, muchas ves a cara de perro. (...) La construcción europea -sigue diciendo el mismo autor-, todavía no está lo suficientemente avanzada y el poder político real recae aún en los Estados miembros, que no tienen ningún interés en que la Comisión Europea tenga unos mecanismos informativos potentes" (Herrero, 1994: 17-18).

La Dirección General X, representante máximo de la estructura comunicativa aunque no en exclusiva, como luego veremos, cuenta desde 1993 con la siguiente organización:

Dirección A: Central de información. Realiza los análisis de la opinión pública, elabora la información y gestiona su archivo documental y sus fuentes de datos.

Dirección B: Redes de información. Coordina las Oficinas de Información propia (Representaciones) y la información que se remite a los países no comunitarios. El papel de las Representaciones está establecido en el documento Comunicación SEC (94) 80/4. Tienen también como misión, la coordinación de los Centros de enlace. "Los centros de enlace e información son estructuras cercanas al público, creadas en organismos preexistentes y con experiencia. Informan a los ciudadanos acerca de la Unión y sus políticas de una manera adaptada e informal. La mayoría de los centros de información se dirigen al gran público y están organizados en redes" (Comisión Europea, 2000: 18). Los enlaces más importantes son: Puntos de Información Europeos o Info Point Europe, Centros de información y animación rural (Carrefours), Centros de Documentación Europea $(\mathrm{CDE})$, Euro Info Centres (EIC) y los Centros de Información Europea (CIE).

Dirección C: Política audiovisual, Cultura y Deporte. Aglutina todas las acciones que promueven la actividad audiovisual en el ámbito comunitario. Su actividad va desde la recogida de información y elaboración de informes semestrales como el de la producción cinematográfica a examen como la atribución de subvenciones de los Fondos del programa Media Plus.

Dirección D: Comunicación. Se encarga de la difusión y elaboración de mensajes para el público en general a través de los diferentes canales, incluido Internet (Informe 1994: 5-15). 
Simultáneamente a la acción comunicativa de la Dirección General X, existen otras instancias de información dependientes de otros organismos pero con contenido especializado. Tal es el caso de Foros Urbanos (centrados en el medio ambiente), Centros Europeos de los consumidores, Eurodesk (formación educativa juvenil), Puntos de Contacto Cultura, Eures (espacio económico europeo), BC- Net, BRE, CEEI/BIC, CEI (información empresarial), Eurojus (Derecho Comunitarioly por último como acciones para el gran público, Europa en Directo y las Casas de Europa, como acción conjunta con la Federación Internacional y las Secciones Nacionales del Movimiento Europeo (Comisión Europea 1998).

No podemos olvidar la acción reguladora de la Unión Europea. Ese derecho derivado exige también una participación de la Organización en la orientación legislativa de los Estados y su función ante las tecnologías que, como decíamos al hablar del Consejo de Europa, cuestionan la soberanía. Se parte siempre de la existencia de una cultura europea, por lo tanto no hay que crear sino incentivar, en colaboración con los Estados y los gobiernos regionales. Este hecho no impide que todavía hoy, E. Bustamante pueda afirmar que "en todo caso, son ya muchos los análisis que subrayan los retrasos europeos en este campo y las dificultades de aprovechar las nuevas circunstancias si no hay una acción política planificada y coherente del Estado a todos los niveles que potencien esas oportunidades" (Bustamante, 2002: 23). La argumentación de pérdida de identidad, sobre todo en la población infantil y juvenil como claro efecto de las series japonesas y norteamericanas involucra claramente a las dos organizaciones máxime cuando se justifica la intervención cultural desde la protección con un pensamiento fielmente platónico. La tecnología audiovisual permite crear o soldar identidades y esta es una idea que no sólo está presente en la teledemocracia de los políticos sino que también fluye en el pensamiento teórico. El miedo a la uniformización cultural propio de la década anterior, deja paso al miedo a la globalización.

Así en 1989 se aprueba la Directiva de la Televisión sin fronteras, introduciendo la cuota obligatoria de pantalla o la inversión en producción europea. La tesis defensiva de la cultura europea se involucra con la de constituir una identidad europea a través de los medios audiovisuales. La Directiva mencionada responde a una tecnología, la vía satélite, y a la pérdida del monopolio público audiovisual en Europa Occidental con la consecuente aparición de las televisiones privadas.

Marca también las nuevas tendencias que regulará respecto al tema la Unión Europea, como en el caso de la protección de los derechos de autor o la protección publicitaria en torno a la infancia y la juventud.

La política francesa de protección de las industrias culturales será asumida por la Unión Europea y defendida, desde entonces, como la cuestión de la excepción cultural, en los foros internacionales, como el conocido con el nombre de la Ronda Uruguay, como la excepción cultural (Mattelart, 2002:129-131). Sin embargo, esta posición será contraria a los planteamientos de los grupos europeos y criticada por los países nórdicos de la Unión. Ante la posible elección de cuotas o inversión o producción, todos los Estados, excepto Francia, optaron masivamente por la política de cuotas. 
El balance del cumplimiento de la Directiva ha sido valorado como muy positivo por la Comisión Europea. Bien es cierto que en esta primera Directiva han sido los propios Estados los que han remitido la información al monitoring, concluyendo el proceso con el Informe de la Comisión.

Para la mayoría de los ciudadanos, la Directiva resulta escasamente conocida y cuestionada. Máxime en el caso español cuando, bajo su reglamentación, se produjo la sobresaturación publicitaria de de emisoras generalistas, siendo sancionada incluso la segunda cadena de TVE. Sin embargo, en Francia, la sanción de emitir en negro durante el tiempo de exceso sancionado, supone un fuerte efecto de credibilidad del medio frente a su audiencia.

En la misma línea la Unión Europea aprobó la Directiva del 97, manteniendo de forma más firme las tesis expuestas en cuanto a producción, distribución y exhibición pero permitiendo, respecto al tiempo de publicidad, la autopromoción a las emisoras y estableciendo distintas modalidades de jurisdicción a los grupos de comunicación audiovisual ${ }^{4}$.

Frente a las sociedades de derechos y la exclusividad de imágenes (especialmente retransmisiones deportivas), la Directiva concede a los Estados la posibilidad de seleccionar anualmente una serie de eventos que serán de interés nacional y emisión en abierto, reservándose también, la posibilidad de emisión en la rejilla de programación (en abierto y en diferido) y el modo de presentación total o parcial.

También ha mantenido su atención respecto a la infancia y la juventud, fijando la necesidad de clasificación programática por parte de los emisores.

Actualmente se encuentra ya en marcha un grupo de trabajo con el objeto de estudiar la reforma del texto vigente y presentar su reforma para el 2005.

En paralelo, se aprobó el programa Media. Criticado como insuficiente en su cuantía presupuestaria duplicará sus fondos en el Media II. Con su propia publicación, denominada del mismo modo, nos anuncia la clasificación de los Estados como receptores de sus subvenciones y cuando habla de esas ayudas hace que apreciemos cómo los grupos de comunicación audiovisual más fuertes a nivel nacional son también los más privilegiados por el Programa Media. Pese a ello, sea bienvenido el Programa Media plus actual (vigente hasta el 2005) y su posible reforma buscando nuevos mecanismos de gestión y financiación como los fondos de titulación norteamericanos. Insuficiente será, pero también necesario, máxime cuando los ciudadanos reclaman desde 1994 la producción propia, en los diferentes formatos audiovisuales, tendencia que no es mundial como podemos apreciar en la audiencia del Mercosur y cuando la incorporación de las nuevas tecnologías nos dispara las horas de programación televisiva.

${ }^{4}$ Directiva $97 / . . . / C E$ del Parlamento Europeo y del Consejo por la que se modifica la Directiva 89/552/CCC del Consejo sobre la coordinación de determinadas disposiciones legales, reglamentarias y administrativas de los Estados miembros relativas al ejercicio de actividades de radiodifusión televisiva. Bruselas, 27 de mayo de 1997. 
El panorama mundial de los medios de comunicación nos muestra un claro dominio de la cultura norteamericana. Así, podemos afirmar que "la televisión americana, los films y la música son comunes en la mayoría de las sociedades a través del globo. En algunos casos, esas importaciones extranjeras dominan incluso la cultura local. Por ejemplo, los films de los Estados Unidos alcanzan en todas partes del $54 \%$ al $92 \%$ de las películas proyectadas en los cines de la Unión Europea. En contraste, las películas europeas alcanzan solamente el $3 \%$ del cine proyectado en la Unión Europea". (Croteaou, Hoyes, 2003: 355). Hay un estilo Hollywood que innegablemente atrae a las audiencias pero también es innegable que sus costes de producción necesitan unos ingresos de carácter global que una industria nacional no puede soportar. Hablar de globalidad es hablar de industria cinematográfica americana. Conforme con Mattelart, será el cine que acuñe por primera vez el concepto de global en la década de los 70 (Mattelart, 1989: 98). Una internacionalización que se basa en los escenarios, en el reparto con la búsqueda de actores de distintas nacionalidades, preferiblemente sin doblar y que se traslada en los mismos términos al mercado de los culebrones latinoamericanos. Distintos rasgos que buscan un mercado pero también la hegemonía y el renombre del mito cinematográfico norteamericano. Dos géneros diferentes unificados por la demanda unificada de la audiencia (Castañares, 1997: 68). Podemos considerar pese a ello, de acuerdo con el Informe Era Digital de la Comisión Europea (Comisión Europea 1998) que actualmente existe una crisis de creatividad y esa sí que no es global. Es una crisis de creatividad en la cinematografía de los Estados Unidos. Aunque el Informe mencionado es de 1998, la crisis del cine estadounidense persiste en la actualidad. Llama la atención el contraste que se ha producido en relación con Europa y, muy en concreto, en relación con España.

\section{EL CARÁCTER GLOBAL DE LA POLÍTICA AUDIOVISUAL}

La política audiovisual europea actual, no ha variado sus principios desde 19995. Los dirigentes europeos son conscientes de la doble naturaleza de sus productos. Por un lado son un bien económico, con un volumen de negocio de 58.300 euros $(+8,7 \%$ frente a 1998) y por otro son factor de la configuración de la identidad como bien cultural que no se puede dejar a los avatares del mercado. "El advenimiento de las nuevas tecnologías -informa la Comisión de las Comunidades Europeas-, no ha afectado al renacimiento del cine en Europa". Se ha demostrado que, "lejos de sustituir a los medios existentes, tales tecnologías ofrecen ingresos adicionales a los operadores del sector"'. Según los estudios realizados por el Observatorio Europeo del Audiovisual podemos apreciar cómo se ha registrado, en el número de entradas vendidas, un incremento del $27 \%$ de 1995 al año 2000. Ello fue debido, en parte, al aumento del número de salas multicines (22\%), durante el mismo período. Este efecto ha incido también en una mejora de la cuota de mercado de las películas no nacionales (10\%), frente a un porcentaje inferior al $8 \%$ en 1996 . Como puede verse, el

\footnotetext{
Principios y directrices para la política audiovisual comunitaria en la era digital. COM (1999) 657 final de 14.12 .1999

- Comisión de las Comunidades Europeas (2001): Comunicación de la Comisión al Consejo, al Parlamento Europeo, al Comité Económico y Social y al Comité de las Regiones, Bruselas, 26.09.2001, COM (2001) 534 final.
} 
ascenso de la cuota del mercado del cine europeo ha sido muy considerable. Sin embargo, aún se halla lejos de alcanzar a la cuota del norteamericano que, en el año 2000 , alcanzó el $73 \%$ de películas norteamericanas con respecto al total de las proyectadas.

La política audiovisual empieza a constituirse como global, recogiéndose actividades conexas con la sociedad de la información, la política cultural, la política regional, los fondos de ayuda financieros y la política educativa. Acciones como el desarrollo de la investigación audiovisual a través del VI Programa Marco se plantean junto a la necesidad de crear un canal de TV de la Unión Europea dedicado a la difusión de obras europeas.

\section{Como medidas de esta acción podemos señalar:}

La creación por parte de la Comisión juntamente con el Banco Europeo de Inversiones (BEI) y el Fondo Europeo de Inversiones (FEI), de la iniciativa "i2i-audiovisual" para completar el programa Media Plus que se centra tanto en los objetivos industriales de mejora de la competitividad como en el fomento de contenidos audiovisuales europeos, partiendo de la diversidad cultural. Además, el Banco Europeo de Inversiones (BEl) a través de la iniciativa "Innovation 2000" ofrece préstamos bancarios para las actividades del sector audiovisual y la industria de contenidos.

El programa "Sociedad de la información" desarrolla actividades de digitalización y explotación de archivos cinematográficos. Así, el programa TEN-Telecom, facilita la creación de servicios multimedia que promuevan el patrimonio cultural europeo, como la creación de archivos audiovisuales. Anualmente CinEd@ays, organiza anualmente jornadas sobre patrimonio cinematográfico europeo para su difusión entre el público general y el educativo. Por último, el Programa eContent, cuyo objetivo es estimular el mercado del contenido digital, se dedica a la creación de bases de datos audiovisuales y el desarrollo de herramientas que faciliten, por ejemplo, la búsqueda de información en varias lenguas y montar el subtitulado de las obras audiovisuales.

La Creación del Foro Europeo del Cine Digital (2001), a instancia sueca, para la elaboración de normas comunes y desarrollo del nuevo mercado electrónico.

La Incorporación de la ayuda de los Fondos Estructurales de la Unión para la creación de infraestructuras en el ámbito audiovisual y multimedia.

El desarrollo de iniciativas educativas en los medios de comunicación en el marco del Programa "elearning" adoptado por la Comisión en marzo de 2001.

La estimulación de la cooperación en el ámbito audiovisual con terceros países, donde se ha alcanzado una fase especialmente avanzada en el marco del Acuerdo de Cotonú y de la asociación euromediterránea.

Respecto a las tendencias del mercado de la industria audiovisual, según el Informe Andersen "Outlook of the development of technologies and markets for the European Audio-visual sector 
up to 2010" (2002), es difícil prever cual será la dirección del mercado audiovisual europeo en el futuro. Sí que se aprecia que la industria audiovisual, en su conjunto se beneficiará de la evolución de la interactividad. No hay que olvidar que los que controlan esta industria tienen además, otros intereses económicos.

\section{REFERENCIAS BIBLIOGRÁFICAS}

- Bustamante, E. y Zallo, R. (1988): Las industrias culturales en España. Grupos multimedia y transnacionales, Madrid: Akal Comunicación.

- Bustamante, E. (1995): "Televisión y dinamización de la industria audiovisual", Pérez Ornia, J.R. (ed.).- La Nueva Perspectiva Audiovisual. El reto de la televisión pública regional, Madrid: Telemadrid.

- Bustamante, E. (ed.) (2002): Comunicación y cultura en la era digital, Barcelona: Gedisa.

- Cebrián, M. (1998): Información Televisiva. Mediaciones, Contenidos, Expresión y Programación, Madrid: Síntesis.

- Castañares, W. (1997): "La televisión y sus géneros: ¿̇una teoría imposible?, Cuadernos de Información y Comunicación, Madrid: Servicio de Publicaciones Universidad Complutense de Madrid, no3, otoño. Castejón, L. (1998): Competencia y regulación en los mercados de las Telecomunicaciones, el Audiovisual e Internet, Madrid: Colegio Oficial de Ingenieros de Telecomunicaciones.

- Cebrián, M. (1998): Información Televisiva. Mediaciones, Contenidos, Expresión y Programación, Madrid: Síntesis.

- Comisión Europea (1997) :Directiva 97/.../CE del Parlamento Europeo y del Consejo por la que se modifica la Directiva $89 / 552 / C C C$ del Consejo sobre la coordinación de determinadas disposiciones legales, reglamentarias y administrativas de los Estados miembros relativas al ejercicio de actividades de radiodifusión televisiva, Bruselas, 27 de mayo de 1997.

- Comisión Europea (1998): Informe Especial, 23/98.

- Comisión Europea (2000): Representación en España

- Croteau, D. \&Hoynes, W. (2003): Media Society. Industries, Images and Audiences, EEUU: Sage Publications, Inc.p.

- Deutsch, K.W (1964): The nerves of government, New York: The Free Press.

- Herrero, S.(1994): "La política informativa de las instituciones comunitarias", Sánchez Martínez, M. (ed.), Periodismo especializado e información comunitaria, Salamanca: Universidad Pontificia de Salamanca.

- "Informe: órganos gubernamentales de información en la Unión Europea y las Naciones Unidas", Cuadernos para el debate 79 (septiembre-octubre 1994), anexo.

- Joyanes, L. (1997): "Cibersociedad; la nueva sociedad de la información (orígenes, evolución e implantación)", Sociedad y Utopía, no9.

- Martín Díez, Mํ. A. (1998): La Estructura de la comunicación en Europa, Madrid: Universidad Europea de Madrid-CEES. 
- Martín Díez, Mํ. A.(2000): "El principio de subsidiariedad como criterio organizador de la comunicación",Banús, E. y Elío, B. (ed.), V Congreso "Cultura Europea", Navarra: Aranzadi.

- Martín Díez, Ma․ A.(2003): "La reforma de la Unión Europea. Una propuesta desde la comunicación", Benavides, J. y Villagra, N. (ed.), Públicos, instituciones y problemas en la comunicación del nuevo milenio, Madrid: Fundación General de la Universidad Complutense.

- Mattelart,A. (1993): La comunicación mundo. Historia de las ideas y de las estrategias, Madrid: Fundesco.

- Mattelart, A. (1997): Historia de las teorías de la comunicación, Barcelona: Paidós.

- Mattelart, A.(2002): Historia de la Sociedad de la Información, Barcelona: Paidós.

- Pérez, J. y Jiménez, P. (2002): La televisión contada con sencillez, Madrid: Nueva Ediciones.

- Sahagún, F. (1998): De Gutenberg a Internet, Madrid: Estudios Internacionales de la Complutense.

- Sánchez-Bravo, A. (1993): La información en la Comunidad Europea, Madrid: Síntesis.

- Sánchez Martínez, M. (1999): Bases de la política de información y comunicación de la Comunidad Europea, Madrid: Centro de Investigaciones Sociológicas.

- Sánchez-Tabernero, A. y Zunzunegui, S. (1994): "La política audiovisual europea", en Sánchez-Tabernero, A. Y Zunzunegui, S., Situación 1994, Bilbao: Servicio de Estudios Banco Bilbao Vizcaya.

- F. Valderrama, Historia de la UNESCO, 2ª ed., París: UNESCO, 1995.

- Wolf, M.(1994): La investigación de la comunicación de masas. Crítica y perspectivas, Barcelona: Paidós. 